\title{
Chromosomal rearrangements, speciation and the theoretical approach
}

Max King
Natural Sciences Division, Museums and Art Galleries of the Northern Territory, PO Box 4646

Darwin N.T., Australia.

Many theoretical papers investigating the relationship between chromosomal change and speciation are found to have been based on erroneous data. For rather than considering those negatively heterotic, or at least potentially negatively heterotic rearrangements which can have a possible role in speciation, these papers have included substantial amounts of information on rearrangements which are not implicated in this process. Common forms of chromosomal repatterning such as heterochromatic addition and polymorphism are in this category. Their inclusion in theoretical studies, of ten cited as supporting or opposing a chromosomal involvement in speciation, invalidates these findings. A new approach is suggested.

\section{INTRODUCTION}

When we consider the systematic array of organisms studied, and the multitude of lifestyle characteristics they exhibit, it is hardly surprising that a number of modes of speciation have been proposed to explain this diversity. Despite this observation, it is clear that certain mechanisms such as the process of genic allopatry (speciation by isolation and genic mutation), are common to many plants and animals. In a great number of groups, a high correlation between chromosomal reorganisation and species diversity has also been found (see White, 1973). Numerous models have been proposed to explain this relationship in terms of chromosomally mediated speciation. Examples such as saltational speciation (Lewis, 1966), stasipatric speciation (White, 1968; 1978), the monobrachial homologies model of Capanna (1982), and primary chromosomal allopatry (King, $1981,1984)$ are but a few of many. In all of these models, negatively heterotic chromosome changes provide the structural basis for reproductive isolation by effecting fertility. There now appears to be a considerable amount of evidence which shows that certain gross chromosomal rearrangements do have substantial fertility effects (see White, 1978; Gropp, 1982; Capanna, 1982), and that they can therefore initiate speciation.

A series of publications has attempted to assess the role played by chromosomal rearrangements in speciation from a theoretical viewpoint (Bush et al., 1977; Imai, 1983), or to ascertain the rate of chromosomal/karyotypic evolution. Their conclusions include the involvement of chromosomes in speciation (Wilson et al., 1975; Coyne, 1984; Larson et al., 1984). Theoretical overviews of this type are often cited as evidence for or against chromosomal speciation, although as in the examples selected, there has been a less than rigorous evaluation of their data base. Indeed. because of errors of unnecessary inclusion, findings made in these studies are at least in doubt and in most cases invalid. The aim of this paper is to highlight some of the problems found in the current theoretical literature and to suggest a more effective approach to this type of analysis.

\section{CATEGORIES OF CHROMOSOME CHANGE}

The single most important criterion is to distinguish between those chromosomal changes which are or can be involved in speciation, and those which can not be. Before analysing the data presented in the above papers, it is important to clarify this concept in some detail. Of the spectrum of chromosomal changes that can occur, it is only those few rearrangements which are negatively heterotic or are potentially negatively heterotic, 
that can possibly play a role in cladogenic processes. These include those rearrangements. which malsegregate at meiosis in structural hybrids, producing aneuploidy, duplications and deficiencies, or which disrupt meiosis entirely. Changes that have the capacity to be powerfully negatively heterotic are tandem fusions, reciprocal translocations, centric fusion or fission, multiple centric fusions, or multiple centric fusions which share brachial homologies (see White, 1973; Capanna, 1982). However, if any of these rearrangements produce a balanced meiotic system, in which normal segregation of the meiotic products occurs, they will no longer be able to form a postmating isolating mechanism and will generally result in chromosomal polymorphisms. It is not at all certain that these disruptive changes will always be involved in speciation, although they clearly have the potential to be so.

A second class of rearrangement is recognisable and this includes both pericentric and paracentric inversions. In this case the data are quite ambiguous as to the involvement of such changes in speciation. Both forms of inversion have the propensity to produce lethal or deleterious meiotic products, the effect of which can be maximised by the localisation of chiasmata (see White, 1973) resulting in dicentric and acentric fragments, but this is not necessarily the course of events. Indeed, it has been suggested on a number of occasions that pericentric or paracentric inversion heterozy. gosity may not have any ill-effects at meiosis (John and King, 1977; King, 1981, John 1981). That is, meiosis can proceed without any deleterious effects in pericentric inversion heterozygotes if chiasma localisation is changed to a terminal position, or is outside the inversion loop. Alternatively, meiotic problems may be prevented by non-homologous pairing in inversion heterozygotes. Analyses of the synaptonemal complexes of inversion heterozyotes in Mus musculus (Davisson et al., 1981) and Peromyscus maniculatus (Greenbaum and Reed, 1984) and standard meiotic analysis of the grasshoppers Camnula pellucida (Nur, 1968), Trimerotropis helferi (Schroeder, 1968) and Cryptobothrus chysophorus (John and King, 1977) found non homologous pairing. However, paracentric inversions induced in laboratory mice did show loop formation in heterozygotes (Moses et al., 1982; Poorman et al., 1981). The status of inversions in the speciation process is thus in doubt.

Clearly, the formation of single inversion differences, unless demonstrably negatively heterotic, may be regarded as a form of chromosome repatterning. Nevertheless, multiple pericen- tric inversions involving many chromosomes in the complement may have a cumulative effect on fertility. Coates and Shaw (1984) proposed that this was the case in their analysis of the grasshopper Caledia captiva where inviability of F2 hybrids suggests that multiple pericentric inversions have the potential to be effective postmating isolating mechanisms. However, in many of the species in which multiple pericentric inversions have been encountered such as the rodents Neotoma micropus (Warner, 1976), Peromyscus species (Greenbaum et al., 1978), and the fish Ilyodon furcidens (Turner et al., 1985), they involve high levels of polymorphism and cannot be claimed to be involved in speciation. The impact of pericentric inversions on speciation is therefore ambiguous and will probably remain so. Paracentric inversions, which are a most common form of chromosome repatterning in organisms such as the Diptera, Chironomidae or Simulidae (White, 1973), and which are also potentially deleterious in their heterozygous state, appear to be in a similar situation; they often occur as balanced polymorphisms and they appear to have a minor role in speciation (see White, 1973; Zouros, 1982).

The third class of change includes those structural rearrangements which we know are not involved in speciation. The two forms of repatterning implicated are first, those neutral or positively heterotic rearrangements which occur as transient or balanced polymorphism, and second, the addition of heterochromatin.

Transient or balanced chromosomal polymorphisms generally have no impact on speciation. The only opportunity such changes might have for an involvement is when a series of transient polymorphisms for sequential chromosome fusions form monobrachial homologies. In meiosis, trivalents or complex chain multiples may result, their complexity being determined by the number of chromosomes sharing homologies within that complement. These may malsegregate with profound effects on fertility, and can therefore act as a postmating isolating mechanism in speciation as proposed by Capanna (1982). Thus, neutral rearrangements have been transformed into negatively heterotic changes. It must be stressed that this is an uncommon situation and involves fixation of the changes, so this is not a true reflection of the effect of polymorphism. However, even if this were the case and complex chain multiples were formed, with the occurrence of balanced segregation such changes could provide no barrier to fertility. Generally, chromosomal polymorphisms which are balanced in their segregation and are neutral or 
adaptive, can not form postmating isolating mechanisms.

There is little evidence to support the involvement of heterochromatic addition in speciation. John and Miklos (1979) have thoroughly dealt with the arguments for and against this form of change. The claims made by Corneo (1976), Fry and Salzer (1977) and Yunis and Yasmineh (1971) remain without support. It is noteworthy that heterochromatin addition is a particularly common form of change in rodents, a group often referred to in speciation studies (see below). Examples showing pronounced C-banding variation include: Patton and Sherwood (1982) in Thomomys; Robbins and Baker (1981), Bradshaw and Hsu (1972), Greenbaum et al., (1978) in Peromyscus; Baker et al., (1979) in Onychomys; Mascarello and Hsu (1976) in Neotoma; Baverstock et al., (1982) in Uromys. These all show heterochromatic blocks in fixed or polymorphic states. There are now numerous studies investigating the effects of chromosomal addition on fertility. In the pocket gopher Thomomys bottae (Patton and Yang (1977)), the white tailed rat Uromys caudimaculatus (Baverstock et al., 1982) the grasshoppers Atractomorpha similis (John and King, 1983) and Cryptobothrus chrysophorus (John and King, 1980), there is no evidence for reduced hybrid fertility between cytotypes possessing gross structural heterozygosity for the amount and localisation of heterochromatin.

At the risk of repetition, it must be emphasised that studies considering the question of speciation and the involvement of chromosomes in this process, should only consider those monomorphic rearrangements which are demonstrably negatively heterotic, or at least have the potential to be so. It is now clear, however, that a number of theoretical papers which are often cited as supporting or opposing the relationship between chromosome change and speciation, are suspect because of the information included in their data bases. These cases are detailed below.

\section{PUBLISHED DATA AND THEORIES}

In a recent paper directed at investigating the relationship between karyotype alteration and species differentiation in mammals, Imai, (1983) made the following assessment of the chromosome rearrangements he used: "Visible chromosome rearrangement denotes in this paper a series of rearrangements changing chromosome number and/or arm number (i.e., Robertsonian rearrange- ment, pericentric inversion, or tandem growth of constitutive heterochromatin in short arms)", (p. 1154).

Further on Imai (1983) tells us: "In a species having chromosome polymorphisms, I count each homomorphic karyotype in a chromosome polymorphism as one," (p. 1155). That is, the analysis that Imai has produced is to a large extent based on chromosomal changes that either have an ambiguous role in speciation (pericentric inversions), or no role in speciation (growth of consitutive heterochromatin and chromosomal polymorphism). Interestingly enough, of the 967 mammals analysed 293 were from the Rodentia, a group in which such chromosome changes predominate. Clearly, these data can not provide a valid comment on speciation. Imai concluded that:

"(1) differentiation of species by speciation without karyotype alteration..."

"(2) substitution of karyotypes in each resulting species..." (p. 1160) predominates in these vertebrates. These findings are at least partially based on data which do not pertain to chromosomal speciation and are therefore spurious.

While Imai's paper argued against chromosome change acting as a primary agent in speciation, a series of other papers which are equally as suspect, have supported the concept of chromosomal speciation. Wilson et al., (1975) Bush et al., (1977) and more recently Larson et al., (1984), have proposed that a relationship exists between social structuring of animal populations, rates of speciation and the involvement of chromosomal change in those processes. The earlier publications have been widely cited in studies involving chromosome change and speciation, although on some occasions not favourably so (see King, 1981; Charlesworth et al., 1982; Bengtsson, 1980). Indeed, King $(1980,1981)$ pointed out that much of the material used by Wilson et al., (1974), Wilson et al., (1975) when discussing reptiles and amphibians was unreliable. When considering chromosomal change, these authors included modifications in chromosome number and arm number. That is, fusions and dissociations, and also pericentric inversions and chromosome additions were utilised (see fig. 1. Wilson et al., 1974; p. 5056). Moreover, they made no distinction between chromosome changes which were polymorphic or fixed, thus casting doubt on any conclusions relating to chromosome change and speciation.

Bush et al., (1977) tested the hypothesis that small demes promote rapid speciation by esimating the rate of chromosomal evolution in 225 genera 
of vertebrates. The authors used what they considered an improved means of estimating the rates of karyotypic change by considering the range in chromosome number and range of chromosome arms per genus. They argued that this approach could estimate the minimum number of chromosomal mutations which must have occurred to produce the observed range of karyotypes. They comment: "Fusions, fissions, and whole-arm inversions are detected, whereas all paracentric inversions, most reciprocal translocations and many pericentric inversions are not. All of the latter are unquestionably important in chromosome evolution and can serve as sterility barriers in speciation" ( $p$. 3942).

This improved means of estimating the rate of chromosomal evolution and of speciation, is still based on the erroneous assumptions found in their earlier publication (Wilson et al., 1974). Heterochromatin addition, a means of chromosomal repatterning common in vertebrates, has been included as have other rearrangements not associated with speciation. It remains unclear whether chromosomal polymorphism has been included or not. Conclusions reached by these authors on the utilisation of structural rearrangements in speciation, or on the life style characteristics which support such processes must remain unsubstantiated.

More recently, Larson et al., (1984) when analysing the relationship between rates of chromosome change, social behaviour and speciation used the same types of raw data, based on the number of chromosomes and chromosome arms. The authors acknowledged: "The structural rearrangements revealed comprise a subset of the total rearrangements taking place: Robertsonian rearrangements (centric fusions and fissions) and whole arm inversions are counted but paracentric inversions are not counted, nor are most interstitial additions and deletions of chromatin" (p. 216).

It would appear that tandem fusions have not been counted, and that whole arm chromosome additions have been. Moreover, it is still not clear whether polymorphisms have been included or not. Once again, the data base incorporates chromosome changes which are irrelevant to the speciation process, and conclusions pertaining to chromosomal involvement in speciation derived from these data are also spurious.

When investigating the correlation between heterozygosity and the rate of chromosome evolution in animals, Coyne (1984) used the data produced by Wilson et al., (1975) and Bush et al., (1977). The conclusions reached by Coyne (1984) on rates of chromosomal evolution were extended to the relationship of chromosomal change to speciation, and to support of the canalisation model of Bickham and Baker (1979). The selection of inappropriate data from discussions on rates of karyotypic/chromosomal evolution (which may well be valid with such data) to speciation (which are not valid) has been made. Indeed, the inference that rates of chromosomal evolution are directly linked to the involvement of chromosomal change in speciation remains unsupported. Only a small portion of those karyotypic changes which have occurred or have reached fixation, have ever had the capacity or potential to be utilized in speciation. Presumably, many structural rearrangements we see in both fixed and polymorphic conditions are either neutral or in some cases adaptive (John and Miklos, 1979; John and King, 1983). While it is undeniable that a high level of chromosomal mutation is essential for chromosomal speciation, estimates of gross rates of chromosomal evolution can tell us a great deal about the level of karyotypic reorganisation, but nothing about speciation.

\section{CONCLUSION}

The purpose of this article has been to suggest that a new approach is required. A more realistic interpretation of the existing chromosomal data on vertebrates could be obtained if they were subdivided into several classes, categorising chromosomal changes which can be expected to play a role in speciation and those which can not. Indeed, further subdivision into individual types of chromosomal rearrangements may be advantageous. Arbitrary subdivisions of this nature when related to such paramaters as social structuring, vagility, and population size, could thus provide a more realistic appraisal of the relationship between chromosomal change and speciation than does the current approach. However, the final arbiter which decides whether a particular rearrangement can or cannot become involved in the speciation process, is the meiotic system of the individual. A complex structural rearrangement may segregate in a balanced fashion in one organism and not in another, and in the final analysis this single event decides whether a rearrangement can ever play a role in speciation.

Acknowledgements Many thanks to Dr Les Christidis and Dr David Hayman and two anonymous reviewers for constructive comments on an earlier version of this manuscript. 


\section{REFERENCES}

BAKER, R. J., BARNETT, R. K. AND GREENBAUM, I. F. 1979. Chromosomal evolution in grasshopper mice (Onychomys: Critetidae) J. Mammal., 60, 297-306.

BAVERSTOCK, P. R., GELDER, M. AND JAHNKE, A. 1982. Cytogenetic studies of the Australian rodent, Uromys caudimaculatus, a species showing extensive heterochromatin variation. Chromosoma (Berl), 84, 517-533.

BENGTSSON, B. O. 1980. Rates of karyotype evolution on placental mammals. Hereditas, 92, 37-47.

BICKHAM, J. W. AND BAKER, R. J. 1979. Canalization model of chromosomal evolution. In Schwartz, J. H. and Rollins, H. G. (eds.) Models and Methodologies in Evolutionary Theory, Bull. Carnegie Mus. Nat. Hist., 13, 70-84.

BRADSHAW, W. N. AND HSU, T. C. 1972. Chromosomes of Peromyscus (Rodentia, Cricetidae). III. Polymorphisms in Peromyscus maniculatus. Cytogenetics, 11, 436-451.

BUSH, G. L., CASE, S. M., WILSON, A. C. AND PATTON, J. B. 1977. Rapid speciation and chromosomal evolution in mammals. Proc. Natl. Acad. Sci. U.S.A., 74, 3942-3946.

CAPANNA, E. 1982. Robertsonian Numerical variation in Animal Speciation: Mus musculus an emblematic model. In "Mechanisms of Speciation", Alan R. Liss, New York, pp. $155-177$.

CHARLESWORTH, B. LANDE, R. AND SLATKIN, M. 1982. A neo Darwinian commentary on macroevolution. Evolution, 36, 474-498.

COATES, D. J. AND SHAw, D. D. 1984. The Chromosomal component of Reproductive isolation in the grasshopper Caledia captiva. III. Chiasma distribution patterns in a new chromosomal Taxon. Heredity, 53, 85-100.

CORNEO, G. 1976. Do satellite DNA's function as sterility barriers in Eukaryotes? Evol. Theory, 1, 261-265.

COYNE, J. A. 1984. Correlation between heterozygosity and rate of chromosome evolution in animals. Amer. Nat., 123, 725-729.

DAVISSON, M. T., POORMAN, P. A., RODERICK, R. H. AND MOSES, M. J. 1981. A pericentric inversion in the mouse. Cytogenet. Cell Genet., 30, 70-76.

FRY, K. AND SALZER, W. 1977. Nucleotide sequences of HSsatellite DNA from kangaroo rat Dipodomys ordii and characterization of similar sequences in other rodents. Cell, 12, 1069-1084.

GREENBAUM, I. F., BAKER, R. J. AND RAMSEY, P. R. 1978. Chromosomal evolution and the mode of speciation in three species of Peromyscus. Evolution, 32, 646-654.

GREENBAUM, I. F. AND REED, M. J. 1984. Evidence for heterosynaptic pairing of the inverted segment in pericentric inversion heterozygotes of the deer mouse (Peromyscus maniculatus). Cytogenet. Cell Genet, 38, 106-111.

IMAI, H. T. 1983. Quantitative analysis of karyotype alteration and species differentiation in mammals. Evolution, 37, 1154-1161.

JOHN, B. 1981. Chromosome change and evolutionary change: a critique. In Atchley, W. R. and Woodruff, D. (eds.) Evolution and Speciation. Essays in honour of M. J. D. White, Cambridge University Press, pp. 23-51.

GROPP, A., WINKING, H. AND REDI, C. 1982. Consequences of Robertsonian heterozygosity: segregational impairment of fertility versus male limited sterility. In P. G. Crosignani, Rubin, B. L. and Fraccaro, M. (eds.) Genetic control of gamete production and function, Academic Press/Grune and Stratton.

JOHN, B. AND KING, M. 1977. Heterochromatin variation in Cryptobothrus chrysophorus. 1. Chromosome differentiation in Natural populations. Chromosoma (Berl.), 64, 219-239.
JOHN, B. AND KING, M. 1980. Heterochromatin variation in Cryptobothrus chrysophorus. 111. Synthetic hybrids. Chromosoma (Berl.), 78, 165-186.

JOHN, B. AND KING, M. 1983. Population cytogenetics of Atractomorphas similis. 1. C-band variation. Chromosoma (Berl.), $88,57-68$.

JOHN, B. AND MIKLOS, G. L. G. 1979. Functional aspects of satellite DNA and heterochromatin. Int. Rev. Cytol., 58, 1-114.

KING, M. 1980. C-banding studies on Australian hylid frogs: secondary constriction structure and the concept of euchromatin transformation. Chromosoma (Berl.), 80, 191-217.

KING, M. 1981. Chromosome Change and speciation in lizards. In Atchley, W. and Woodruff, D. (eds.), Essays on Evolution and Speciation in Honour of M. J. D. White, Camb. Univ. Press, pp. 262-285.

KING, M. 1984. Karyotypic evolution in Gehyra (Gekkonidae, Reptilia). IV. Chromosome change and speciation. Genetica, 64, 101-114.

LEWIS, H. 1966. Speciation in Flowering plants. Science, 152, $167-172$.

LARSON, A., PRAGER, E. M. AND WILSON, A. C. 1984. Chromosomal evolution, speciation and morphological change in vertebrates: the role of social behaviour. In Chromosomes Today, 8, Bennett, M. D., Gropp, A. and Wolf, U. (eds.), George Allen and Unwin, London, pp. 215-228.

MASCARELlo, J. T. AND HSU, T. C. 1976. Chromosome evolution in woodrats, genus Neotoma (Rodentia: Cricetidae). Evolution, 30, 152-169.

MOSES, M. J., POORMAN, P. A., RODERICK, T. H. AND DAVISSON, M. T. 1982. Synaptonemal complex analysis of mouse chromosomal rearrangements. IV. Synapsis and synaptic adjustment in two paracentric inversions. Chromosoma (Berl.), 84, 457-474.

NUR, U. 1968. Synapsis and crossing, over within a paracentric inversion in the grasshopper Camnula pellucida. Chromosoma (Berl.), 25, 198-214.

PATTON, J. L. AND YANG, S. Y. 1977. Genetic variation in Thomomys bottae pocket gophers: macrogeographic patterns. Evolution 31, 697-720.

PATTON, J. L. AND SHERWOOD, S. W. 1982. Genome evolution in pocket gophers (genus Thomomys). 1. Heterochromatin variation and speciation potential. Chromosoma (Berl.), $85,149-162$.

POORMAN, P. A., MOSES, M. J., DAVISSON, M. T. AND RODERICK, T. H. 1981. Synaptonemal complex analysis of mouse chromosomal rearrangements. 111. Cytogenetic observations on two paracentric inversions. Chromosoma (Berl.), 83, 419-429.

ROBBINS, L. W. AND BAKER, R. J. 1981. An assessment of the nature of chromosomal rearrangements in 18 species of Peromyscus (Rodentia: Cricetidae). Cytogenet. Cell. Genet., 31, 194-202.

SCHROEDER, G. L. 1968. Pericentric inversion polymorphism in Trimerotropis helferi (Orthoptera: Acrididae) and its effect on chiasma frequency. Ph.D thesis. Univ. California at Davis.

TURNER, B. J., GRUDZIEN, T. A., ADKISSON, K. P. AND WORRELL, R. A. 1985. Extensive chromosomal divergence within a single river basin in the Goodeid fish, Ilyodon furcidens. Evolution, 39, 122-134.

WARNER, J. W. 1976. Chromosomal variation in the plains woodrat: geographic distribtuion of three chromosomal morphs. Evolution, 30, 593-598.

WhITE, M. J. D. 1968. Models of Speciation. Science, 159, 10651070 . 
WhITE, M. J. D. 1973. Animal cytology and evolution, Third Edition, Cambridge Univ. Press.

WHITE, M. J. D. 1978. Modes of Speciation, Freeman, San Francisco.

WILSON, A. C., SARICH, V. M. ANI) MAXSON, L. R. 1974. The importance of gene rearrangement in evolution: evidence from studies on rates of chromosomal, protein and anatomical evolution. Proc. Nat. Acad. Sci. U.S.A., 71, 30283030 .
WILSON, A. C., BUSH, G. L., CASE, S. M. AND KING, M. C. 1975. Social structuring of mammalian populations and rate of chromosomal evolution. Proc. Nat. Acad. Sci. U.S.A., 72, 5061-5065.

YUNIS, J. J. AND YASMINEH, W. G. 1971. Heterochromatin, Satellite DNA, and cell function. Science, 174, 1200-1209. zoUROS, E. 1982. On the role of chromosomal inversions in speciation. Evolution, 36, 414-416. 